\title{
Dietary antioxidants decrease serum soluble adhesion molecule (sVCAM-1, sICAM-1) but not chemokine (JE/MCP-1, KC) concentrations, and reduce atherosclerosis in C57BL but not apoE*3 Leiden mice fed an atherogenic diet
}

\author{
Nuala Murphy ${ }^{\mathrm{a}}$, David C Grimsditch ${ }^{\mathrm{b}}$, Martin Vidgeon-Hart ${ }^{\mathrm{c}}$, Pieter H.E. Groot ${ }^{\mathrm{b}}$, Philip Overend ${ }^{\mathrm{d}}$, \\ G. Martin Benson ${ }^{\mathrm{b}}$ and Annette Graham ${ }^{\mathrm{a}, *}$ \\ ${ }^{a}$ Department of Biochemistry and Molecular Biology, Royal Free and University College Medical School of UCL, \\ Royal Free Campus, Rowland Hill Street, London NW3 2PF, UK \\ ${ }^{\mathrm{b}}$ Departments of Atherosclerosis, GlaxoSmithKline Pharmaceuticals, Gunnels Wood Road, Stevenage, Herts, SG1 \\ $2 N Y, U K$ \\ ${ }^{c}$ Neurology, Statistical Sciences, GlaxoSmithKline Pharmaceuticals, New Frontiers Science Park (North), Harlow, \\ Essex, CM19 5AD, UK \\ ${ }^{\mathrm{d}}$ Statistical Sciences, GlaxoSmithKline Pharmaceuticals, New Frontiers Science Park (North), Harlow, Essex, \\ CM19 5AD, UK
}

\begin{abstract}
Dietary antioxidants are reported to suppress cellular expression of chemokines and adhesion molecules that recruit monocytes to the artery wall during atherosclerosis. In the present study we measured the effect of feeding apoE*3 Leiden mice or their non-transgenic (C57BL) littermates with atherogenic diets either deficient in, or supplemented with, dietary antioxidants (vitamin $\mathrm{E}$, vitamin $\mathrm{C}$ and $\beta$-carotene) for 12 weeks, on serum levels of $\mathrm{CC}$ (JE/MCP-1) and CXC (KC) chemokines and soluble adhesion molecules (sVCAM-1, sICAM-1) and atherosclerotic lesion size.

ApoE*3 Leiden mice developed gross hypercholesterolaemia, and markedly accelerated $(10-20$ fold; $P<0.0001)$ atherogenesis, compared with non-transgenic animals. Antioxidant consumption reduced lesion area in non-transgenic, but not apoE*3 Leiden, mice. Serum sVCAM-1 and sICAM-1 levels were significantly $(P<0.0001)$ increased (sVCAM-1 up to 3.9 fold; sICAM-1 up to 2.4 fold) by $4-8$ weeks in all groups, and then declined. The initial increase in the concentration of adhesion molecules was reduced by $38 \%-61 \%(P<0.05)$ by antioxidant consumption, particularly in non-transgenic mice. By contrast, serum chemokine levels tended to increase more rapidly from baseline in apoE*3 Leiden mice, compared with non-transgenic animals, but were unaffected by dietary antioxidants. We conclude that dietary antioxidants reduce circulating soluble adhesion molecules and atherosclerosis in C57BL mice.
\end{abstract}

Keywords: Atherosclerosis, antioxidant, adhesion molecule, chemokine

${ }^{*}$ Corresponding author: Dr. A Graham, Department of Biological and Biomedical Sciences, School of Life Sciences, Glasgow Caledonian University, Cowcaddens Road, Glasgow G4 0BA. Tel.: +44
141331 3722; Fax: +44 141331 3208; E-mail: Ann.Graham@ gcal.ac.uk. 


\section{Introduction}

Oxidative stress can activate members of the Rel family of transcription factors, notably nuclear factor- $\kappa \mathrm{B}$ $(\mathrm{NF}-\kappa \mathrm{B})$, and increase endothelial expression of proinflammatory genes encoding chemokines and adhesion molecules involved in monocyte recruitment to the artery wall during atherosclerosis [1-3]. Cell adhesion molecules of the immunoglobulin superfamily (IgSF), such as Vascular Cell Adhesion Molecule-1 (VCAM1) and Intercellular Cell Adhesion Molecule-1 (ICAM1 ), are involved in the firm adhesion of monocytes to the endothelium [1-3]. Soluble adhesion molecules are found in the circulation, following 'shedding' of these molecules from cells by proteolytic cleavage at a site close to the transmembrane domain [4]. Elevated serum concentrations of sVCAM-1and sICAM-1 are linked with inflammatory disorders and coronary heart disease [5-13]. Thus, elevated levels of s VCAM1 [5,8-12] and sICAM-1 [5-8,12] are found in patients with aortic and carotid atherosclerosis [8-11], aortic aneurysms [7], peripheral vascular disease [5] and unstable angina [12]. Significantly, emerging data suggest that elevated levels of SICAM-1 may be predictive of future risk of coronary artery disease $[6,13]$, while sVCAM-1 levels are strongly prognostic of the extent and severity of existing atherosclerosis [9-11], reviewed in [13].

Chemokines are members of a superfamily of small secreted proteins that mediate migration and activation of leukocytes and arterial cells [14]. Chemokines are divided into families according to the arrangement of the first two of four conserved cysteine residues, the two largest being designated CC and CXC [14]. Members of the $\mathrm{CC}$ (or $\beta$ ) subfamily predominantly chemoattract monocytes and T-lymphocytes, but not neutrophils, and extensive experimental evidence supports a role for the prototypical CC chemokine, Monocyte Chemotactic Protein-1 (MCP-1) in the monocytic infiltration that characterises atherosclerosis $[15,16]$. Chemokines of the CXC (or $\alpha$ ) family, particularly those like interleukin-8 (IL-8) that contain the ELR (Glu-Leu-Arg) motif, principally induce the migration of neutrophils, and not monocytes [14]. However, despite this apparent selectivity, and the scarcity of neutrophils within atherosclerotic lesions [17], recent data also implicates members of the CXC chemokine subfamily in monocyte recruitment and/or retention during atherogenesis [18].

Circulating levels of chemokines are increased in several acute and chronic inflammatory and immune- related disorders [19-23], suggesting their levels may reflect enhanced tissue expression and secretion of these molecules during disease. Elevated levels of CC [19,20,23] and CXC [21-23] chemokines have been reported in patients with congestive heart failure [19,21], restenosis after balloon angioplasty [20], ischaemia-reperfusion injury [22] or aortic aneurysms [23], and seem to be associated with the degree of disease severity [19,20].

Dietary antioxidants can prevent NF- $\kappa \mathrm{B}$ activation, suppress cellular expression of chemokines and adhesion molecules [1-3], and reduce lesion development in some [24,25] but not all [26] murine models of atherosclerosis, although their efficacy in humans is less convincing [27]. Here, we monitor systemic levels of CC (JE/MCP-1) and CXC (KC) chemokines and soluble adhesion molecules (sVCAM-1, sICAM-1) in apoE*3 Leiden mice or their non-transgenic (C57BL) littermates, consuming an atherogenic diet deficient in, or supplemented with, dietary antioxidants (vitamin E, vitamin $\mathrm{C}$ and $\beta$-carotene) for up to 12 weeks.

\section{Mathrials and methods}

\subsection{Mice, feeding protocol and sample collection}

Transgenic mice expressing both apoE*3 Leiden (identified by ELISA for human apoE) and apoC1 transgenes were generated exactly as previously described [28]. Mating male transgene carriers with C57BL/6J females produced subsequent generations. Non-transgenic littermates were used as controls. In the present study, 60 female mice (30 transgenic and 30 non-transgenic) aged 8-10 weeks were allocated randomly to experimental groups on the basis of age and litter, and housed in groups of 5. Mice had free access to food and water, and were maintained in specific pathogen-free conditions throughout the study.

Animals were maintained on a standard rat/mouse diet (RM1; Special Diet Services) before the experimental period. During the study (0-12 weeks), mice were fed a high-fat/high-cholesterol/cholate (HFC) containing diet (below), supplied by Hope Farms, and formulated according to Nishina et al. [29] to minimize liver damage. The diet contains cocoa butter $(15 \%)$, sodium cholate $(0.5 \%)$, cholesterol $(1 \%)$, sucrose $(40.5 \%)$, cornstarch $(10 \%)$, corn oil (1\%), cellulose $(4.7 \%)$, casein $(20 \%), 50 \%$ w/v choline chloride $(2 \%)$, methionine $(0.2 \%)$ and vitamin/mineral mixtures $(5.1 \%)$. The diet was modified so that it was either de- 
ficient in $\beta$-carotene and vitamin $\mathrm{C}$, and contained a reduced content of vitamin E $(<0.03 \%$, w/w) (HFC/Low Antioxidant [LAO]), or supplemented with vitamin $\mathrm{E}$ $(0.1 \%, \mathrm{w} / \mathrm{w}), \beta$-carotene $(0.5 \%, \mathrm{w} / \mathrm{w})$ and vitamin $\mathrm{C}$ $(0.05 \%, \mathrm{w} / \mathrm{w})(\mathrm{HFC} / \mathrm{High}$ Antioxidant [HAO]). In total, groups of 15 apoE*$^{*} 3$ Leiden mice, and 15 of their non-transgenic littermates were fed either HFC/LAO diet or HFC/HAO diet. The procedures involving animals in this study were subject to internal review and UK Home Office regulations.

Blood samples $(250 \mu \mathrm{l})$ were taken from the tail vein at weeks 0,4 and 8 , at least four hours after the start of the light phase when food consumption is minimal. Post-mortem samples $(600 \mu \mathrm{l})$ were taken from the aorta immediately after the mice were culled. Total serum cholesterol and triglyceride concentrations were measured enzymatically using commercially available kits (Boehringer Mannheim).

\subsection{Measurement of serum chemokine and soluble adhesion molecule concentrations}

$\mathrm{JE}$ and $\mathrm{KC}$ concentrations were determined in diluted serum samples (1:1-1:4), using commercially available ELISA kits (R\&D Systems) (30). Soluble ICAM-1 levels were determined in diluted serum samples (1:100), using a commercially available ELISA kit (Endogen). Soluble VCAM-1 levels were determined in diluted serum samples (1:20) using an ELISA established in this laboratory, using polyclonal (R\&D Systems) and monoclonal (Endogen) anti-murine VCAM-1 antibodies, and recombinant murine VCAM-1 as a standard (R\&D Systems).

\subsection{Tissue preparation and lesion analysis}

After 12 weeks of diet feeding, mice were culled and their hearts perfused-fixed in situ with oxygenated Krebs buffer at $37^{\circ} \mathrm{C}$ (30 min, ca $100 \mathrm{~cm}$ water pressure), followed by neutral-buffered formalin (4\%, v/v) (25 $\mathrm{min}$, ca $100 \mathrm{~cm}$ water pressure). Hearts were dissected, embedded in OCT compound, and sectioned $(10 \mu \mathrm{m})$ as described previously [31]. Serial sections were stained with Oil-Red-O, counterstained with Cole's haematoxylin and used for quantitation of lesion development [30,31]. Lesion cross-sectional area was determined by morphometric evaluation of ten alternate sections of the aortic root, commencing where the three valve leaflets first appeared [30,31]. Images were analysed using an Olympus BH-2 microscope and computer controlled video-imaging system, and quantified exactly as previously described [30,31].

\subsection{Statistical analysis}

All the parameters described, except lesion areas, were log-transformed in order to normalise the variances, and geometric means with $95 \%$ confidence intervals are quoted. Parameters describing lesion areas (lesion cross-sectional area and Oil-Red-O stained area within the lesion) were transformed by taking the square root of the raw data values. A mixed model split-plot analysis of variance was used to analyse the atherosclerotic lesion area in the four groups of mice. The analysis accounted for variability in lesion areas caused by the generally increasing size of lesions in the 10 serial sections taken at specific locations within the aortic sinus, as well as variability between mouse strain and diet. Comparisons of the four groups of mice at the first Section 1, middle Section 5.5 and final Section 10 were made using the LSD test. The significance of the LSD test P-values were then examined further using the Benjamini-Hochberg method, in ordid the false positive results possible when a large number of multiple comparisons are being made.

The following comparisons were made between the groups of mice used: $\mathbf{a}_{\mathrm{apoE}^{*} 3}$ Leiden mice (HFC/HAO) versus apoE*3 Leiden (HFC/LAO); $\mathbf{b}_{\text {apoE*3 Leiden }}$ (HFC/HAO) versus non-transgenic

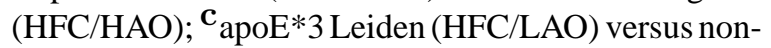
transgenic (HFC/LAO); and $\mathbf{d}_{\text {non-transgenic }(\mathrm{HFC} /}$ $\mathrm{HAO})$ versus non-transgenic (HFC/LAO). Differences were considered statistically significant if $P<0.05$; NS, non-significant.

\section{Results}

\subsection{Lipids and lesion development}

Consumption of HFC diet for up to 12 weeks induced significant $(P<0.05)$ increases in serum cholesterol levels that were consistently 4-8 fold higher $(P<0.05)$ in the apoE*3 Leiden mice compared with their non-transgenic littermates (Table 1), as described previously [30,31]. ApoE*3 Leiden mice consuming diet HFC/LAO had significantly $(37 \% ; P<0.05)$ higher cholesterol levels at week 8 only, compared with apoE*3 Leiden mice consuming diet HFC/HAO. By contrast, serum cholesterol levels were $35 \%$ lower $(P<0.05)$ in the non-transgenic animals consuming diet HFC/LAO, compared with those fed diet $\mathrm{HFC} / \mathrm{HAO}$. 
Table 1

Effect of diet and strain of mouse on serum cholesterol and triglyceride concentrations

\begin{tabular}{|c|c|c|c|c|c|c|}
\hline \multirow{2}{*}{$\begin{array}{l}\text { Table } 1 \\
\text { Mice/Diet/Week }\end{array}$} & \multicolumn{3}{|c|}{ Serum cholesterol mg/dl } & \multicolumn{3}{|c|}{ Serum triglyceride $\mathrm{mg} / \mathrm{dl}$} \\
\hline & Lower CI & Geometric mean & Upper CI & Lower CI & Geometric mean & Upper CI \\
\hline \multicolumn{7}{|l|}{ apoE*3Leiden/HAO } \\
\hline 0 weeks & 123.3 & 137.9 & 154.3 & 291.0 & 328.1 & 369.9 \\
\hline 4 weeks & 1299.3 & 1452.1 & 1622.8 & 197.4 & 231.4 & 271.2 \\
\hline 8 weeks & 1319.3 & 1504.4 & 1715.4 & 121.4 & 148.2 & 180.9 \\
\hline 12 weeks & 1452.8 & 1657.1 & 1890.2 & 190.5 & 242.2 & 308.1 \\
\hline \multicolumn{7}{|l|}{ apoE*3Leiden/LAO } \\
\hline 0 weeks & 121.6 & 136.6 & 153.5 & 250.3 & 284.9 & 324.3 \\
\hline 4 weeks & 1479.3 & 1674.3 & 1895.0 & 106.8 & $126.6^{\mathrm{a}}$ & 150.1 \\
\hline 8 weeks & 1801.0 & $2073.7^{\mathrm{a}}$ & 2387.7 & 121.2 & 150.1 & 185.9 \\
\hline 12 weeks & 1583.6 & 1818.4 & 2088.1 & 123.1 & 158.4 & 203.8 \\
\hline \multicolumn{7}{|l|}{ NTG/HAO } \\
\hline 0 weeks & 68.6 & $76.5^{\mathrm{b}}$ & 85.3 & 93.7 & $105.2^{\mathrm{b}}$ & 118.1 \\
\hline 4 weeks & 270.4 & $302.2^{\mathrm{b}}$ & 337.7 & 22.3 & $26.1^{\mathrm{b}}$ & 30.6 \\
\hline 8 weeks & 308.7 & $352.1^{\mathrm{b}}$ & 401.4 & 21.1 & $25.7^{\mathrm{b}}$ & 31.4 \\
\hline 12 weeks & 449.0 & $509.5^{\mathrm{b}}$ & 578.2 & 38.5 & $48.5^{\mathrm{b}}$ & 61.1 \\
\hline \multicolumn{7}{|l|}{$N T G / L A O$} \\
\hline 0 weeks & 80.3 & $88.9^{\mathrm{c}}$ & 98.5 & 101.4 & $113.1^{\mathrm{c}}$ & 126.0 \\
\hline 4 weeks & 226.5 & $251.4^{\mathrm{C}}$ & 279.1 & 27.7 & $32.2^{\mathrm{c}}$ & 37.4 \\
\hline 8 weeks & 288.21 & $326.0^{\mathrm{c}}$ & 368.8 & 24.5 & $29.6^{\mathrm{c}}$ & 35.6 \\
\hline 12 weeks & 294.4 & $331.0^{\mathrm{c}, \mathrm{d}}$ & 372.2 & 40.4 & $50.0^{\mathrm{C}}$ & 61.9 \\
\hline \multicolumn{7}{|c|}{$\begin{array}{l}\text { Effect of diet and strain of mouse on serum cholesterol and triglyceride concentrations in apoE*3 Leiden mice } \\
(n=15) \text { or their non-transgenic littermates }(n=15) \text { consuming either the antioxidant-replete diet, HFC/HAO, } \\
\text { or the antioxidant-deficient diet, HFC/LAO. Values shown are geometric means } \pm 95 \% \text { confidence intervals }(\mathrm{CI}) \text {. } \\
\text { a significant difference }(p<0.05) \text { between apoE*3 Leiden mice consuming HFC/HAO and HFC/LAO; }{ }^{b} \text { significant } \\
\text { difference }(p<0.05) \text { between apoE*3 Leiden mice consuming HFC/HAO and non-transgenic animals consuming } \\
\text { HFC/HAO; }{ }^{\mathrm{c}} \text { significant difference }(p<0.05) \text { between apoE*3 Leiden and non-transgenic mice consuming HFC/LAO } \\
\text { and }{ }^{\mathrm{d}} \text { significant difference }(p<0.05) \text { between non-transgenic animals consuming either HFC/HAO or HFC/LAO. }\end{array}$} \\
\hline
\end{tabular}

Serum triglyceride concentrations were significantly (3-8fold; $P<0.05$ ) higher in both groups of apoE*3 Leiden mice throughout the study, compared with their non-transgenic littermates (Table 1). The presence of antioxidants did not affect serum triglyceride concentrations in the non-transgenic animals. However, at week 4 only, higher $(82 \%, P<0.05)$ serum triglycerides were seen in the group of apoE*3 Leiden mice consuming diet HFC/HAO, compared with those fed HFC/LAO (Table 1).

The hyperlipidaemia in apoE*3 Leiden mice fed HFC diet, compared with their non-transgenic littermates, was associated with markedly accelerated atherogenesis in these animals (Table 2). Both OilRed-O staining, and lesion area, were 10-20 fold larger $(P<0.05)$ in the apoE*3 Leiden mice than in the nontransgenic controls (Table 2). When lesion section areas were compared, significant $(P<0.05)$ differences were detected between groups of non-transgenic mice consuming HFC/HAO and HFC/LAO. The presence of dietary antioxidants reduced $(P<0.05)$ lesion areas in the middle section (5.5) (2008 versus $5505 \mu \mathrm{m}^{2}$ ) and final [10] (1270 versus $\left.3867 \mu \mathrm{m}^{2}\right)$ sections from non-transgenic mice. Significant $(P<0.05)$ reduc- tions in Oil-Red-O staining were observed in the middle section of these lesions ( 942 versus $2494 \mu \mathrm{m}^{2}$ ) with a trend towards reduction in the final section (560 versus $1749 \mu \mathrm{m}^{2}$, NS). No significant differences were detected in apoE*3 Leiden mice fed either HFC/HAO or $\mathrm{HFC} / \mathrm{LAO}$ diets.

\subsection{Systemic concentrations of soluble adhesion molecules and chemokines}

Serum levels of sVCAM-1 were equivalent in all groups of mice at the start of this study (Fig. 1). Large increases $(P<0.0001)$ in serum sVCAM-1 concentrations from baseline occurred in both groups of animals fed the antioxidant-deficient diet (HFC/LAO), rising 2.9-3.9 fold by week 4 of the study (Fig. 1a). Levels of sVCAM-1 were highest in the non-transgenic group of animals consuming HFC/LAO diet. Consumption of dietary antioxidants (HFC/HAO) significantly $(P<0.05)$ blunted this response in the nontransgenic and apo $\mathrm{E}^{*} 3$ Leiden mice (by $61 \%$ and $38 \%$, respectively). After 8 weeks, levels of sVCAM-1 were still higher $(P<0.05)$ in the non-transgenic animals consuming HFC/LAO (1.3 fold). By week 12, how- 
Table 2

Effect of diet and strain of mouse on atherosclerotic lesions

\begin{tabular}{cllccc} 
Table 2 & & \multicolumn{4}{c}{ Lesion area $\left(\mu \mathrm{m}^{2} \times 10^{3}\right)$} \\
Section & Strain & Diet & Lower CI & LS Mean & Upper CI \\
1 & ApoE*3Leiden & HAO & 38.0 & 46.4 & 55.7 \\
1 & ApoE*3Leiden & LAO & 35.4 & 43.5 & 52.5 \\
1 & NTG & HAO & 2.22 & $4.05^{\mathrm{b}}$ & 6.41 \\
1 & NTG & LAO & 3.48 & $5.54^{\mathrm{c}}$ & 8.08 \\
5.5 & ApoE*3Leiden & HAO & 49.6 & 58.8 & 68.7 \\
5.5 & ApoE*3Leiden & LAO & 50.6 & 59.8 & 69.8 \\
5.5 & NTG & HAO & 0.863 & $2.01^{\mathrm{b}}$ & 3.63 \\
5.5 & NTG & LAO & 3.56 & $5.50^{\mathrm{c}, \mathrm{d}}$ & 7.87 \\
10 & ApoE*3Leiden & HAO & 46.8 & 56.1 & 66.3 \\
10 & ApoE*3Leiden & LAO & 51.2 & 61.0 & 71.5 \\
10 & NTG & HAO & 0.368 & $1.27^{\mathrm{b}}$ & 2.71 \\
10 & NTG & LAO & 2.18 & $3.87^{\mathrm{c}, \mathrm{d}}$ & 6.02 \\
& & & $0 i 1-\mathrm{Red}^{*} \mathrm{O}$ area $\left(\mu \mathrm{m}^{2} \times 10^{3}\right)$ \\
1 & ApoE*3Leiden & HAO & 20.6 & 25.5 & 31.0 \\
1 & ApoE*3Leiden & LAO & 21.0 & 26.0 & 31.6 \\
1 & NTG & HAO & 0.986 & $1.93^{\mathrm{b}}$ & 3.20 \\
1 & NTG & LAO & 1.74 & $2.87^{\mathrm{c}}$ & 4.27 \\
5.5 & ApoE*3Leiden & HAO & 28.0 & 33.4 & 39.3 \\
5.5 & ApoE*3Leiden & LAO & 30.2 & 35.8 & 41.8 \\
5.5 & NTG & HAO & 0.366 & $0.942^{\mathrm{b}}$ & 1.79 \\
5.5 & NTG & LAO & 1.53 & $2.49^{\mathrm{c}, \mathrm{d}}$ & 3.70 \\
10 & ApoE*3Leiden & HAO & 25.2 & 30.7 & 36.6 \\
10 & ApoE*3Leiden & LAO & 30.6 & 36.5 & 43.0 \\
10 & NTG & HAO & 0.123 & $0.560^{\mathrm{b}}$ & 1.31 \\
10 & $\mathrm{NTG}^{*}$ & LAO & 0.900 & $1.75^{\mathrm{c}}$ & 2.88
\end{tabular}

Effect of feeding diets HFC/HAO and HFC/LAO for 12 weeks on Oil-Red-O staining intensity and cross-sectional area of atherosclerotic lesions in the aortic roots of apoE*3 Leiden $(n=15)$ and their non-transgenic littermates (NTG; $n=15$ ). Values shown are means $\pm 95 \%$ confidence intervals, derived from the LSD test; conclusions regarding the significance of the LSD test p-values were made using the Benjamini-Hochberg method

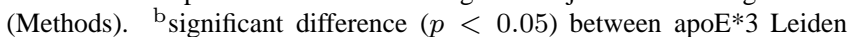
mice and non-transgenic animals consuming $\mathrm{HFC} / \mathrm{HAO} ;{ }^{\mathrm{c}}$ significant difference $(p<0.05)$ between apoE*3 Leiden and non-transgenic mice consuming $\mathrm{HFC} / \mathrm{LAO},{ }^{\mathrm{d}}$ significant difference $(p<0.05)$ between non-transgenic animals consuming HFC/HAO and HFC/LAO.

ever, all groups of animals showed a decline in circulating sVCAM-1 towards baseline levels.

Serum sICAM-1 concentrations were slightly higher (1.20-1.45 fold; $P<0.05$ ) in the two groups of apoE*3 Leiden mice, compared with their nontransgenic controls, at the start of the study (Fig. 1b). It was also noteworthy that levels of sICAM-1 were considerably higher than concentrations of sVCAM1. Circulating levels of sICAM-1 increased significantly $(P<0.05)$ in all groups of mice $(1.8-2.4$ fold $)$ following consumption of the atherogenic (HFC) diet. Antioxidant consumption did not affect sICAM-1 levels in apoE*3 Leiden mice. However, at weeks 4 and 8, non-transgenic animals consuming HFC/LAO had significantly higher (64\% and $36 \%$ respectively; $P<0.05)$ levels of sICAM-1 than the group of nontransgenic mice consuming HFC/HAO (Fig. 1b). Fur- ther, at weeks 8 and 12 , apoE*3 Leiden mice consuming diet HFC/HAO had significantly higher $(46 \%$ and $62 \%$ respectively; $P<0.05$ ) levels of sICAM-1 than nontransgenic animals consuming the same diet. Again, by week 12, all groups of animals showed a decline in circulating levels of sICAM-1 towards baseline levels.

Serum concentrations of CC (JE/MCP-1) and CXC (KC) chemokines were equivalent in all groups of animals at the start of the study (Figs $2 \mathrm{a}$ and $\mathrm{b}$ ). Consumption of the atherogenic (HFC) diet caused rapid increases $(P<0.0001)$ from baseline in serum JE and $\mathrm{KC}$, that were not affected by the presence or absence of dietary antioxidants, in any of the groups of mice. Serum JE (Fig. 2a) and KC (Fig. 2b) concentrations tended to increase more rapidly in apoE*3 Leiden mice than in the non-transgenic controls, so that at 8 weeks, circulating levels of JE were 2.7 and 2.4- 
(a)

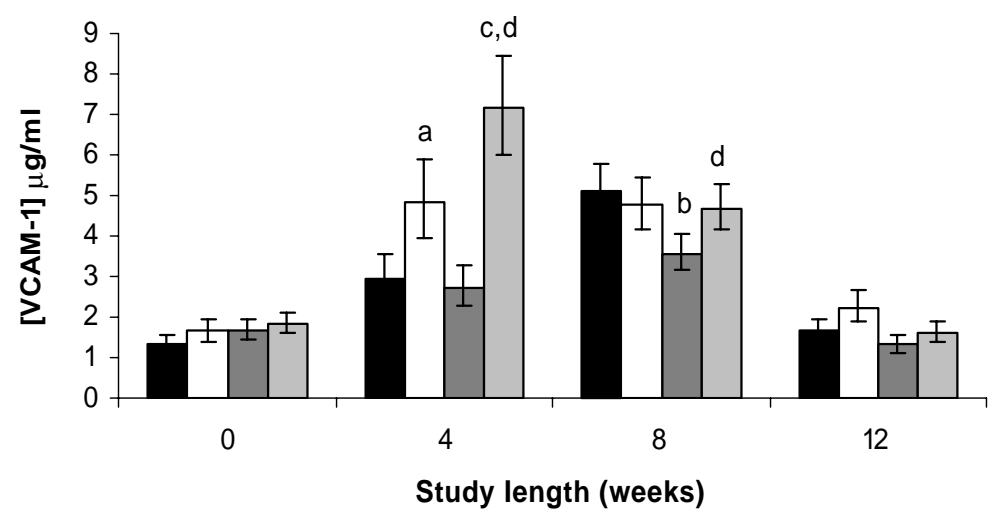

(b)

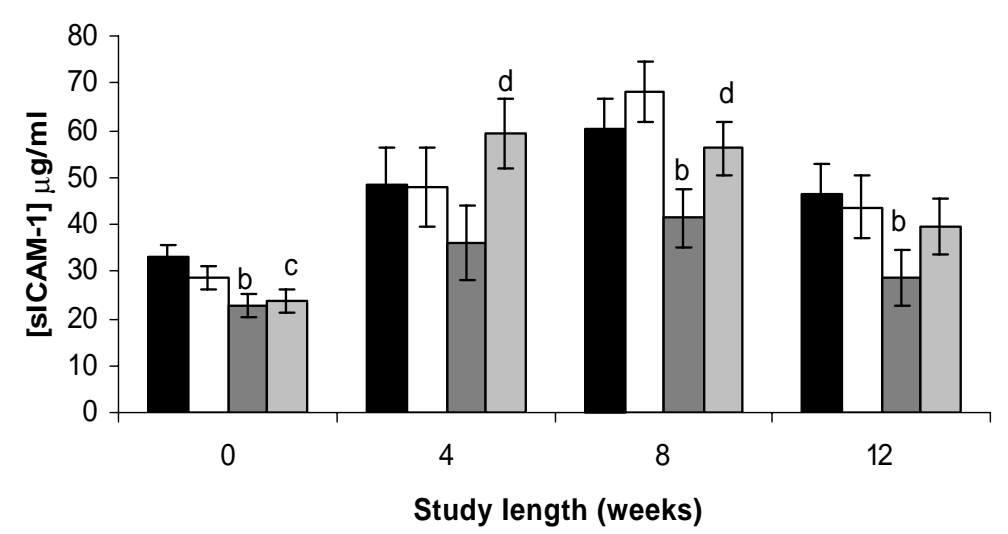

Fig. 1. Effect of diet and strain of mouse on serum SVCAM-1 (a) and sICAM-1 (b) concentrations in apoE*3 Leiden mice $(n=15)$ or their non-transgenic littermates $(n=15)$ consuming either the antioxidant-replete diet, HFC/HAO, or the antioxidant-deficient diet, HFC/LAO. Values shown are geometric means $\pm 95 \%$ confidence intervals. ${ }^{a}$ significant difference $(p<0.05)$ between apoE*3 Leiden mice consuming HFC/HAO and HFC/LAO; ${ }^{\mathrm{b}}$ significant difference $(p<0.05)$ between $\mathrm{apoE}^{*} 3$ Leiden mice and non-transgenic animals consuming $\mathrm{HFC} / \mathrm{HAO} ;{ }^{\mathrm{c}}$ significant difference $(p<0.05)$ between apoE*3 Leiden and non-transgenic mice consuming HFC/LAO and ${ }^{\mathrm{d}}$ significant difference $(p<0.05)$ between non-transgenic animals consuming either HFC/HAO or HFC/LAO. Data are geometric means $\pm 95 \%$ confidence intervals.

fold $(P<0.05)$ higher in the apoE*3 Leiden mice consuming HFC/HAO and HFC/LAO diets, compared with their non-transgenic controls. Similarly, after 8 weeks serum KC levels were significantly (2.2-fold; $P<0.05)$ higher in the group of apoE*3 Leiden mice consuming diet $\mathrm{HFC} / \mathrm{HAO}$, compared with nontransgenic animals consuming the same diet. However, by week 12, all groups of animals had approximately equivalent elevated serum JE and $\mathrm{KC}$ concentrations.

\section{Discussion}

This study demonstrates the ability of dietary antioxidants (vitamin $\mathrm{E}$, vitamin $\mathrm{C}$ and $\beta$-carotene) to modulate systemic levels of soluble adhesion molecules (sVCAM-1, sICAM-1), but not CC (JE/MCP-1) or CXC (KC) chemokines, during development of atherosclerotic lesions in hypercholesterolaemic apoE*3 Leiden mice, and their non-transgenic littermates.

Previous studies in humans have suggested elevated circulating soluble adhesion molecules as 'markers' of endothelial dysfunction and/or underlying cardiovascular disease [5-12], although contrasting reports have emerged regarding their association with hyperlipidaemia [13]. In mice, hypercholesterolaemia increases VCAM-1 and ICAM-1 expression by the arterial endothelium, prior to the development of atherosclerotic lesions [32,33]. Initial circulating concentrations of sICAM-1, but not sVCAM-1, were significantly higher in apoE*3 Leiden mice compared with their non-transgenic littermates. This suggests that sICAM1 levels may be particularly sensitive to mild perturba- 


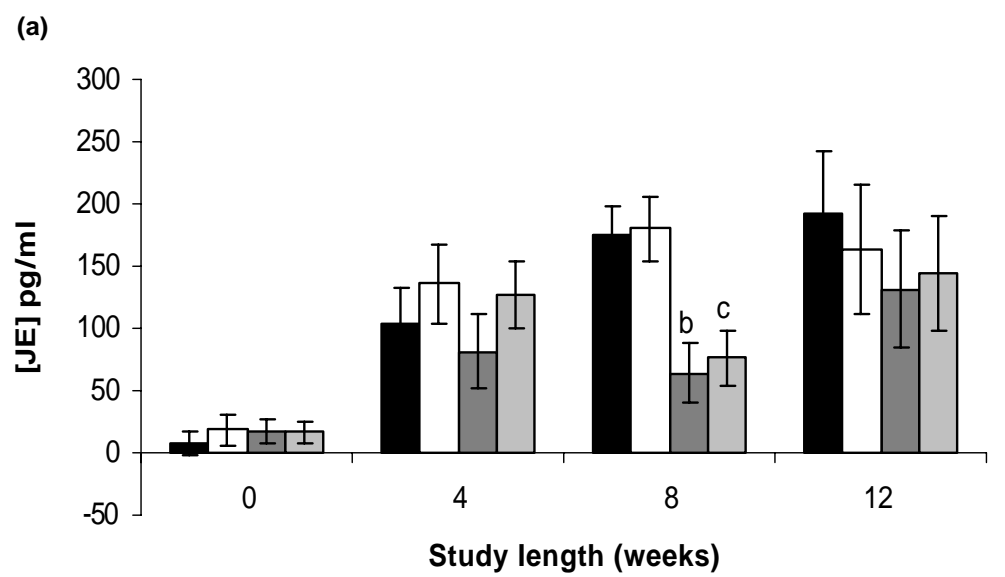

(b)

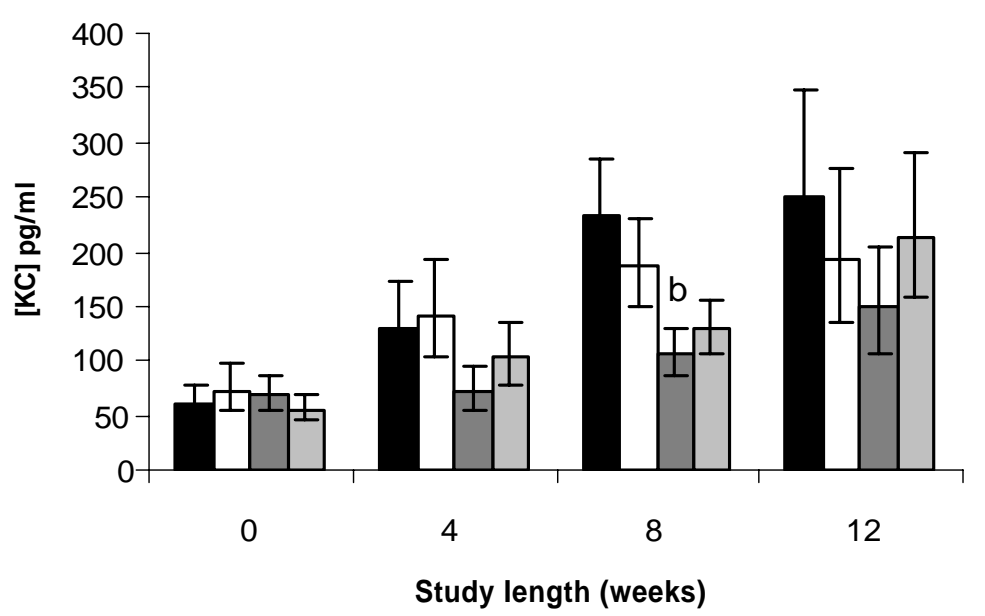

Fig. 2. Effect of diet and strain of mouse on serum JE (a) and KC (b) levels in apoE*3 Leiden mice $(n=15)$ or their non-transgenic littermates $(n=15)$ consuming either the antioxidant-replete diet, HFC/HAO, or the antioxidant-deficient diet, HFC/LAO. Values shown are geometric means $\pm 95 \%$ confidence intervals. ${ }^{\text {a }}$ significant difference $(p<0.05)$ between apoE* 3 Leiden mice consuming HFC/HAO and $\mathrm{HFC} / \mathrm{LAO} ;{ }^{\mathrm{b}}$ significant difference $(p<0.05)$ between apoE*3 Leiden mice and non-transgenic animals consuming $\mathrm{HFC} / \mathrm{HAO} ;{ }^{\mathrm{c}}$ significant difference $(p<0.05)$ between apoE*3 Leiden and non-transgenic mice consuming HFC/LAO and ${ }^{\mathrm{d}}$ significant difference $(p<0.05)$ between non-transgenic animals consuming either $\mathrm{HFC} / \mathrm{HAO}$ or $\mathrm{HFC} / \mathrm{LAO}$. Data are geometric means $\pm 95 \%$ confidence intervals.

tions in serum lipids in apoE*3 Leiden mice fed normal diet. Alternatively, expression of the dominant mutated human apoE*3 Leiden transgene could abrogate the reported anti-inflammatory effects of wild-type apoE. At later stages of the study, serum levels of sICAM1 and sVCAM-1 were significantly higher in apoE*3 Leiden mice fed HFC/HAO diet, compared with the non-transgenic controls. However, it is clear that a direct, proportional relationship between absolute concentrations of soluble adhesion molecules and serum lipids does not exist.

Equally, these serum concentrations of sICAM-1 and SVCAM-1 did not predict the markedly different rates of progression, or extent of atheroma achieved, in apoE*3 Leiden mice, and their non-transgenic littermates, fed a HFC diet. Both sICAM-1 and sVCAM-1 increased to maximal systemic levels 4 or 8 weeks after diet initiation and then declined towards baseline, suggesting that their serum concentrations reflect only one component of the complex inflammatory and proliferative process involved in lesion development. Previous reports suggest that expression of VCAM-1 and ICAM-1 are prevalent in early fatty streaks, but are down-regulated as the plaque evolves from a fatty to a fibrous stage $[32,33]$. However, changes in the proteolytic generation of soluble adhesion molecules [4], and/or their clearance from the circulation, may explain the observed decline in SICAM-1 and SVCAM-1 in the 
serum.

The presence or absence of dietary antioxidants appears to be a major factor modulating serum levels of sVCAM-1 and sICAM-1. Antioxidant supplements have variously been shown to induce significant, if relatively modest (5-25\%), reductions in SICAM-1 and sVCAM-1 in healthy volunteers [34], hypercholesterolaemic individuals [35], and in patients with type II diabetes [36]. However, these dietary interventions failed to change systemic levels of soluble adhesion molecules in smokers, either with [37] or without evident hyperlipidaemia [38]. Here, the pro-inflammatory effects of the atherogenic (HFC) diet [39], as judged by circulating levels of sICAM-1 and sVCAM-1, were amplified by antioxidant deficiency, particularly in the non-transgenic mice.

This sensitivity to antioxidant supplementation was reflected in the effect of antioxidants on lesion development in these groups of animals. Significant differences in lesion size were detected in the non-transgenic mice consuming $\mathrm{HFC} / \mathrm{HAO}$ versus $\mathrm{HFC} / \mathrm{LAO}$ diet. However, no such differences were apparent in apoE*3 Leiden mice, where lesion development is highly correlated with hypercholesterolaemia [30,31]. The different anti-atherogenic effects of antioxidants in the two strains of mice may have been affected by the different rates of lesion progression in these mice. ApoE*3 Leiden mice fed HFC diet may be too severe a model of lesion development to detect the anti-atherogenic effect of antioxidants. However, it must be recognised that an apparent dichotomy exists between laboratory studies and human clinical trials investigating antioxidant efficacy [27,40-42]. Dietary antioxidants have proved beneficial in epidemiological studies, but to lack protective effects (or even be harmful) in the majority of controlled clinical trials investigating the relationship between antioxidant intake and cardiovascular or allmortality outcomes [27,40-42]. For example, Miller et al. (2005) concluded from their recent meta-analysis that high-dosage vitamin E supplementation may increase all-cause mortality [40]. Equally, the most recent primary prevention study investigating the efficacy of vitamin E, the Women's Health Study, reported no overall benefit for major cardiovascular events, cancer or total mortality [41].

Current dogma also suggests that activation of the Rel/NF- $\kappa \mathrm{B}$ family of transcription factors results in a coordinated up-regulation of adhesion molecules and chemokines [1-3]. One study, using cytokine profiling by antibody array, has detected significant decreases in serum MCP-1 in healthy human volunteers taking vi- tamin E supplements (800IU, 8 weeks) [43]. However, responses to vitamin $\mathrm{E}$ was variable within the group of individuals tested [43]. Our previous work showed that hypercholesterolaemic apoE*3 Leiden mice exhibit elevated serum concentrations of both $\mathrm{CC}$ (JE/MCP-1) and $\mathrm{CXC}$ (KC, Macrophage Inflammatory protein-2 (MIP-2)) chemokines [30]. However, in this model, serum chemokine concentrations did not reflect temporal aortic production of these molecules, and proved less predictive than serum cholesterol of the differing rates of atheroma in apoE*3 Leiden and nontransgenic mice [30]. This study, using a modified form of the same diet deficient in, or supplemented with, dietary antioxidants, essentially confirms these findings and, intriguingly, shows that serum chemokine concentrations are unaffected by consumption of dietary antioxidants. The underlying reason(s) for the differential sensitivities of sVCAM-1, sICAM-1, JE and KC, to dietary antioxidants in apoE*3 Leiden and C57BL mice fed a high fat, high cholesterol diet, is not clear, but provides support for the measurement of soluble adhesion molecules, rather than serum chemokines, in assessing systemic inflammatory responses in future laboratory or human studies of antioxidant efficacy. Our findings also seem to indicate the necessity for monitoring the efficacy of dietary interventions in vivo, rather than using in vitro studies.

\section{Conclusion}

Our results suggest that dietary antioxidants modulate circulating soluble adhesion molecules (sVCAM1, sICAM-1), but not chemokines (JE, KC), and reduce atherosclerosis in non-transgenic (C57BL), but not apoE*3 Leiden, mice.

Abbreviations used: HAO diet, antioxidant supplemented diet; HFC diet, high fat, high cholesterol diet containing sodium cholate; ICAM-1, Intercellular Adhesion Molecule-1; LAO diet, antioxidant deficient diet; MCP-1, Monocyte Chemotactic Protein-1; NF- $\kappa$ B, Nuclear Factor- $\kappa$ B; VCAM-1, Vascular Cell Adhesion Molecule-1.

\section{Acknowledgements}

We gratefully acknowledge the support of a BBSRC/CASE GlaxoSmithKline studentship [NM]. 


\section{References}

[1] W. Erl, C. Weber, C. Wardemann and P.C. Weber, $\alpha$ tocopherol succinate inhibits monocytic cell adhesion to endothelial cells by suppressing NF- $\kappa \mathrm{B}$ mobilisation, Am $J$. Physiol. 273 (1997), H634-640.

[2] L. Cominacini, U. Garbin, A.F. Pasini, A. Davoli, M. Campagnola, G.B. Contessi, A.M. Pastorino and V. Lo Cascio, Antioxidants inhibit the expression of intercellular cell adhesion molecule-1 and vascular cell adhesion molecule- 1 induced by oxidized LDL on human umbilical vein endothelial cells, Free Rad. Biol and Med. 22 (1997), 117-127.

[3] D. Wu, T. Koga, K.R. Martin and M. Meydani, Effect of vitamin $\mathrm{E}$ on human aortic endothelial cell production of chemokines and adhesion to monocytes, Atherosclerosis 147 (1999), 297-307.

[4] A.J.H. Gearing and W. Newman, Circulating adhesion molecules in disease, Immunology Today 14 (1993), 506-512.

[5] A.D. Blann, M. Seigneur, M. Steiner, P.J. Miller and C.N. McCollum, Circulating ICAM-1 and VCAM-1 in peripheral artery disease and hypercholesterolaemia: relationship to the location of atherosclerotic disease, smoking, and in the prediction of adverse events, Thromb. Hemost. 79 (1998), 10801085.

[6] P.M. Ridker, C.H. Hennekens, B. Roitman-Johnson, M.J. Stampfer and J. Allen, Plasma concentration of soluble intercellular adhesion molecule 1 and risks of future myocardial infarction in apparently healthy men, The Lancet 351 (1998), 88-92.

[7] Z. Szekanecz, M.R. Shah, W.H. Pearce and A.E. Koch, Intercellular adhesion molecule-1 (ICAM-1) expression and soluble ICAM-1 (sICAM-1) production by human aortic endothelial cells: a possible role for ICAM-1 and sICAM-1 in atherosclerotic aortic aneurysms, Clin. Exp. Immunol. 98 (1994), 337-343.

[8] L.E. Rohde, R.T. Lee, J. Rivero, M. Jamacochian, L.H. Arroyo, W. Briggs, N. Rifai, P. Libby, M.A. Creager and P.M. Ridker, Circulating cell adhesion molecules are correlated with ultrasound-based assessment of carotid atherosclerosis, Arterioscler. Thromb. Vasc. Biol. 18 (1998), 1765-1770

[9] K. Nakai, C. Itoh, K. Kawazoe, Y. Miura, H. Sotoyanagi, K. Hotta, T. Itoh, J. Kamata and K. Hiramori, Concentration of soluble vascular cell adhesion molecule-1 (VCAM1) correlated with expression of VCAM-1 mRNA in the human atherosclerotic aorta, Coronary Artery Disease 6 (1995), 497-502.

[10] K. Peter, P. Nawroth, C. Conradt, T. Nordt, T. Weiss, M. Boehme, A. Wunsch, J. Allenberg, W. Kubler and C. Bode, Circulating Vascular Cell Adhesion Molecule-1 correlates with the extent of human atherosclerosis in contrast to circulating Intercellular Adhesion Molecule-1, E-selectin, P-selectin and thrombomodulin, Arterioscler. Thromb. Vasc. Biol. 17 (1997), 505-512.

[11] R. De Caterina, G. Basta, G. Lazzerini, G. Dell'Omo, R. Petrucci, M. Morale, F. Carmassi and R. Pedrinelli, Soluble Vascular Cell Adhesion Molecule-1 as a biohumoral correlate of atherosclerosis, Arterioscler. Thromb. Vasc. Biol. 17 (1997), 2646-2654.

[12] N. Mulvihill, J.B. Foley, N. Ghaisas, R. Murphy, P. Crean and M. Walsh, Early temporal expression of soluble cellular adhesion molecules in patients with unstable angina and subendocardial myocardial infarction, American Journal of Cardiology 83 (1999), 1265-1267.
[13] S. Blankenberg, S. Barbaux and L. Tiret, Adhesion molecules and atherosclerosis, Atherosclerosis 170 (2003), 191-203.

[14] J.M. Wang, W. Gong and J.J. Oppenheim, Chemokines, receptors, and their role in cardiovascular pathology, Int. J. Clin. Lab. Res. 28 (1998), 83-90.

[15] L. Gu, S.K. Okada, C. Gerard, G.K. Sukhova, P. Libby and B.J. Rollins, Absence of monocyte chemoattractant protein1 reduces atherosclerosis in low-density lipoprotein receptordeficient mice, Molecular Cell 2 (1998), 275-281.

[16] J. Gosling, S. Slaymaker, L. Gu, S. Tseng, C.H. Zlot, S.G. Young, B.J. Rollins and I.F. Charo, MCP-1 deficiency reduces susceptibility to atherosclerosis in mice that overexpress human apolipoprotein B, J. Clin. Invest. 103 (1999), 773-778.

[17] L. Jonasson, T. Holne, O. Skalli, G. Bondjers and G.K. Hansson, Regional accumulations of T-cells, macrophages and smooth muscle cells in the human atherosclerotic plaque, $\mathrm{Ar}$ teriosclerosis 6 (1986), 131-138.

[18] W.A. Boisvert, R. Santiago, L.K. Curtiss and R.A. Terkeltaub, A leukocyte homologue of the IL- 8 receptor CXCR-2 mediates the accumulation of macrophages in atherosclerotic lesions of LDL receptor-deficient mice, J. Clin. Invest. 101 (1998), 353-363.

[19] P. Aukrust, T. Ueland, F. Muller, A.K. Andreassen, I. Nordoy, H. Aas, J. Kjekskhus, S. Simonsen, S.S. Froland and L. Gullestad, Elevated circulating levels of CC chemokines in patients with congestive heart failure, Circulation 97 (1998), 1136-1143.

[20] F. Cipollone, M. Marini, M. Fazia, B. Pini, A. Iezzi, M. Reale, L. Paloscia, G. Materzzo, E. Di'Annunzio, P. Conti, F. Chiarelli, F. Cuccurullo and A. Mezzetti, Elevated circulating levels of monocyte chemoattractant protein-1 in patients with restenosis after coronary angioplasty, Artero. Thromb. Vasc. Biol. 21 (2001), 327-334.

[21] J.K. Damas, L. Gullestad, T. Ueland, N.O. Solum, S. Simonsen, S.S. Froland and P. Aukrust, CXC-chemokines, a new group of cytokines in congestive heart failure - possible role of platelets and monocytes, Cardiovascular Research 45 (2000), $421-436$.

[22] G.L. Kukielka, K.A. Youker, L.H. Michael, A.G. Kumar, C.M. Ballantyne, C.W. Smith and M.L. Entman, Role of early reperfusion in the induction of adhesion molecules and cytokines in previously ischaemic myocardium, Mol. Cell Biochem. 147 (1995), 5-12.

[23] A.E. Koch, S.L. Kunkel, W.H. Pearce, M.R. Shah, D. Parikh, H.L. Evanoff, G.K. Haines, M.D. Burdick and R.M. Strieter, Enhanced production of the chemotactic cytokines interleukin- 8 and monocyte chemoattractant protein-1 in human abdominal aortic aneurysms, Am. J. Pathol 142 (1993), 1423-1431.

[24] D. Practico, R.K. Tangirala, D.J. Rader, J. Rokach and G.A. Fitzgerald, Vitamin E suppresses isoprostane generation in vivo and reduces atherosclerosis in apoE-deficient mice, $\mathrm{Na}$ ture Medicine 4 (1998), 1189-1192.

[25] R.S. Crawford, E.A. Kirk, M.E. Rosenfeld, R.C. LeBoeuf and A. Chait, Dietary antioxidants inhibit development of fatty streak lesions in the LDL receptor-deficient mouse, Arterio. Thromb. Vasc. Biol. 18 (1998), 1506-1513.

[26] A. Shaish, J. George, B. Gilburd, P. Keren, H. Levkovitz and D. Harats, Dietary $\beta$-carotene and $\alpha$-tocopherol combination does not inhibit atherogenesis in an apoE-deficient mouse model, Arterio. Thromb. Vasc. Biol. 19 (1999), 1470-1475.

[27] R. Mashima, P.K. Witting and R. Stocker, Oxidants and antioxidants in atherosclerosis, Curr. Opin. Lipidol. 12 (2001), $411-418$. 
[28] A.M.J.M. Van den Maagdenberg, M.H. Hofgker, P.J.A. Kripenfort, I. de Brujin, B. van Vlijmen, H. van der Boom, L.N. Havekes and R.R. Frants, Transgenic mice carrying the apolipoprotein $\mathrm{E}^{*} 3$ Leiden gene exhibit hyperlipoproteinaemia, J. Biol. Chem. 268 (1993), 10540-10545.

[29] P.M. Nishina, J. Vertuyft and B. Paigen, Synthetic low and high fat diets for the study of atherosclerosis in the mouse, $J$. Lipid Res. 31 (1990), 859-869.

[30] N. Murphy, K.R. Bruckdorfer, D.C. Grimsditch, P. Overend, M. Vidgeon-Hart, P.H.E. Groot, G.M. Benson and A. Graham, Temporal relationships between circulating levels of CC and CXC chemokines and developing atherosclerosis in apoE*3 Leiden mice, Arterioscler. Thromb. Vasc. Biol. 23 (2003), 1615-1620.

[31] P.H.E. Groot, B.J.M. van Vlijmen, G.M. Benson, M.H. Hofker, R. Schiffelers, M. Vidgeon-Hart and L.M. Havekes, Quantitative assessment of aortic atherosclerosis in APOE*3 Leiden transgenic mice and its relationship to serum cholesterol exposure, Arterio. Thromb. Vasc. Biol. 16 (1996), 923-933.

[32] K. Iiyama, L. Hajra, M. Iiyama, H. Li, M. DiChiara, B.D. Medoff and M.I. Cybulsky, Patterns of Vascular Cell Adhesion Molecule-1 and Intercellular Adhesion Molecule-1 expression in rabbit and mouse atherosclerotic lesions and at sites predisposed to lesion formation, Circ. Res. 85 (1999), 199-207.

[33] K. Zibara, E. Chignier, C. Covacho, R. Poston, G. Canard, P. Hardy and J. McGregor, Modulation of expression of Endothelial Intercellular Adhesion Molecule-1, PlateletEndothelial Cell Adhesion Molecule-1, and Vascular Cell Adhesion Molecule-1 in aortic arch lesions of apolipoprotein Edeficient compared with wild-type mice, Arterioscler. Thromb. Vasc. Biol. 20 (2000), 2288-2296.

[34] B. van Dam, V.M.M. van Hinsbergh, C.D.A. Stehouwer, A. Versteilen, D. Dekker, R. Buytenhek, H.N. Princen and C.G. Schlkwijk, Vitamin E inhibits lipid peroxidation-induced adhesion molecule expression in endothelial cells and decreases soluble cell adhesion molecules in healthy subjects, Cardiovasc. Res. 57 (2003), 563-571.

[35] G. Desideri, M.C. Marinucci, G. Tomassoni, P.G. Masci, A. Santucci and C. Ferri, Vitamin E supplementation reduces plasma vascular cell adhesion molecule-1 and von Willebrand factor levels and increases nitric oxide concentrations in hypercholesterolaemic patients, J Clin Endocrinol. Metab. 87 (2002), 2940-2945.

[36] S. Deveraj and I. Jialal, Low density lipoprotein postsecretory modification, monocyte function and circulating adhesion molecules in Type 2 diabetic patients with and without macrovascular complications, Circulation 102 (2000), 191196.

[37] L.J.H. van Tits, F. deWaart, H.L. Hak-Lemmers, van P. Heijst, J. de Graaf, P.N.M. Demacker and A.F.H. Stalenhoef, Effects of $\alpha$-tocopherol on superoxide production and plasma intercellular adhesion molecule- 1 and antibodies to oxidized LDL in chronic smokers, Free Rad. Biol. Med. 30 (2001), 1122-1129.

[38] I. Seljeflot, H. Arnesen, I.R. Brude, M.S. Nenseter, C.A. Drevon and I. Hjermann, Effects of omega-3 fatty acids and/or antioxidants on endothelial cell markers, Eur J Clin Invest 28 (1998), 629-635.

[39] F. Liao, A. Andalibi, J.-H. Qiao, H. Allayee, A.M. Fogelman and A.J. Lusis, Genetic evidence for a common pathway mediating oxidative stress, inflammatory gene induction, and aortic fatty streak formation in mice, J. Clin. Invest. 94 (1994), $877-884$.

[40] I.M. Lee, N.R. Cook, J.M. Gaziano, D. Gordon, P.M. Ridker, J.E. Manson, C.H. Hennekens and J.E. Buring, Vitamin E in the primary prevention of cardiovascular disease and cancer: the Women's Health Study: a randomised controlled trial, JAMA 294 (2005), 56-65.

[41] E.R. Miller, R. Pastor-Burriuso, D. Dalal, R.A. Rimersma, L.J. Appel and E. Gullar, Meta-analysis: High-dosage vitamin E supplementation may increase all-cause mortality, Ann Intern. Med. 142 (2005), 37-46.

[42] E.R. Greenberg, Vitamin E supplements: good in theory, but is the theory good? Ann Intern. Med. 142 (2005), 75-76.

[43] Y. Lin, R. Huang, N. Santanam, Y-G. Liu, S. Parthsarathy and R.-P. Huang, Profiling of human cytokines in healthy individuals with vitamin E supplementation by antibody array, Cancer Letters 187 (2002), 17-24. 


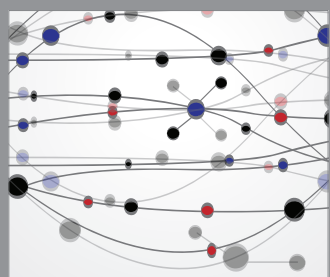

The Scientific World Journal
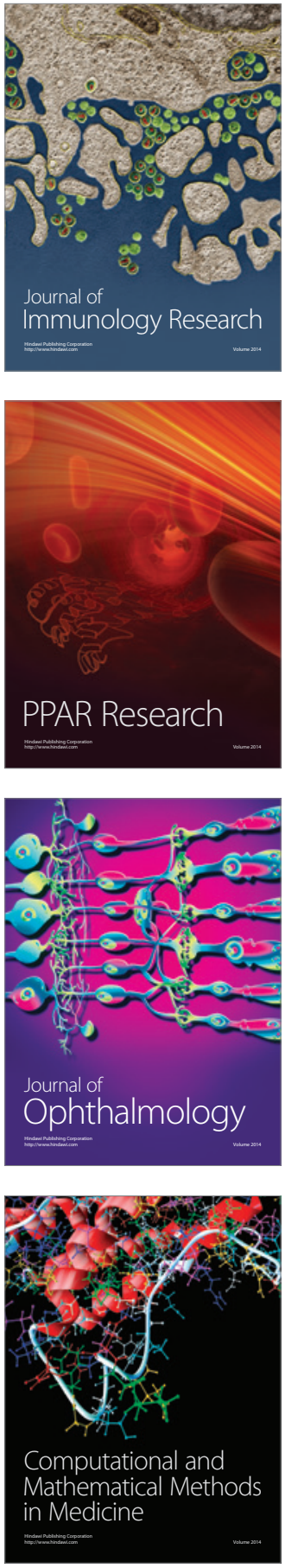

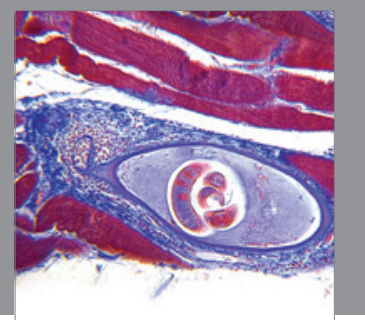

Gastroenterology

Research and Practice
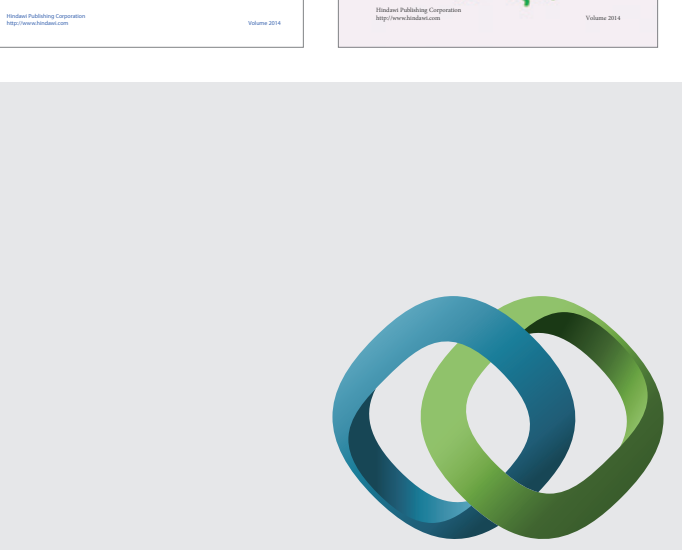

\section{Hindawi}

Submit your manuscripts at

http://www.hindawi.com
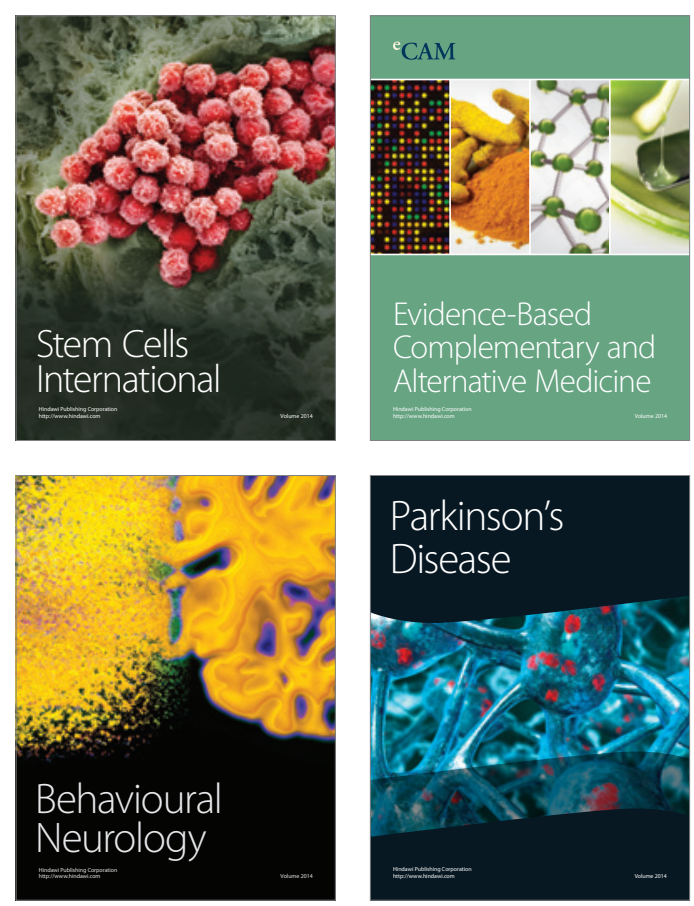

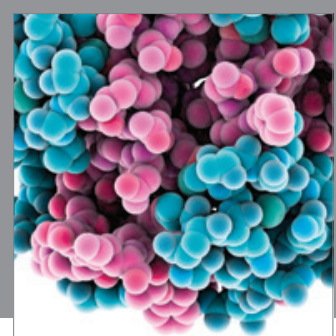

Journal of
Diabetes Research

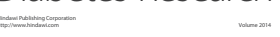

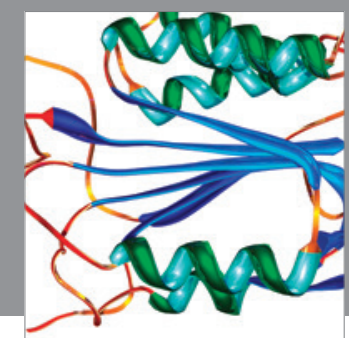

Disease Markers
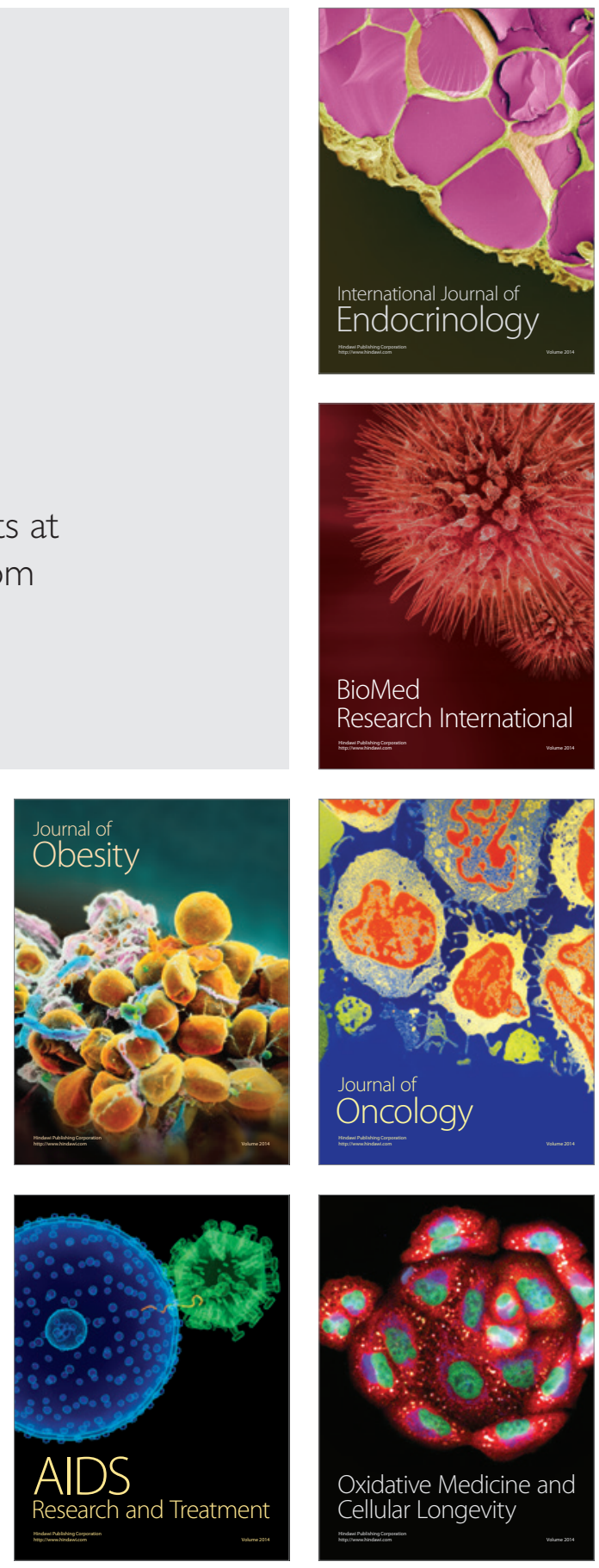